\section{Jürgen Aschoff (1913-98)}

\section{Pioneer in biological rhythms}

For chronobiology, an era came to an end with the death of Jürgen Aschoff on 12

October at the age of 85 . Along with his younger friend Colin Pittendrigh, whom he survived by two years (see Nature 381, $24 ; 1996)$, Aschoff was regarded as the founder of the study of biological rhythms. Together they laid out the conceptual framework for our current understanding of, and vigorous enquiry into, the temporal organization of life as it has evolved on a rotating planet.

The youngest son of a famous father the Freiburg pathologist Ludwig Aschoff - Jürgen grew up in the liberal but morally strict milieu of Prussian academia. He studied medicine at the University of Bonn, then moved to the University of Göttingen where his scientific career began. There, his teacher Hermann Rein worked on thermoregulation physiology, inspiring Aschoff to follow in his footsteps (he was able to keep Aschoff out of the war, as indispensible for the training of physicians). After the war, Aschoff lectured at the University of Würzburg, and a gifted teacher he turned out to be.

In 1952 Rein was appointed director at the new Max Planck Institute for Medical Research in Heidelberg. He took his brightest student with him as a collaborator. Experimenting on himself, Aschoff discovered spontaneous 24-hour variations in human heat loss. This aroused his interest in the mechanism behind such patterns. It was known that activity rhythms in animals persisted in constant conditions and were endogenously generated. Raising birds from the egg, and breeding mice for several generations in constant conditions, Aschoff established that this rhythmicity was innate: no previous exposure to the 24-hour day was required to evoke it.

In the late 1950s Konrad Lorenz and Erich von Holst lured Aschoff to their new Max Planck Institute of Behavioural Physiology (MPIV) in Bavaria. There he built his own department dedicated to the study of biological timing. As a physician among behavioural biologists, he grasped the opportunity of studying humans and animals in parallel. In birds and mammals, he investigated the sensitivity of endogenous circadian systems to environmental stimuli. The intensity of continuous illumination modulated their frequency in predictable though opposite ways in nocturnal and diurnal animals, a

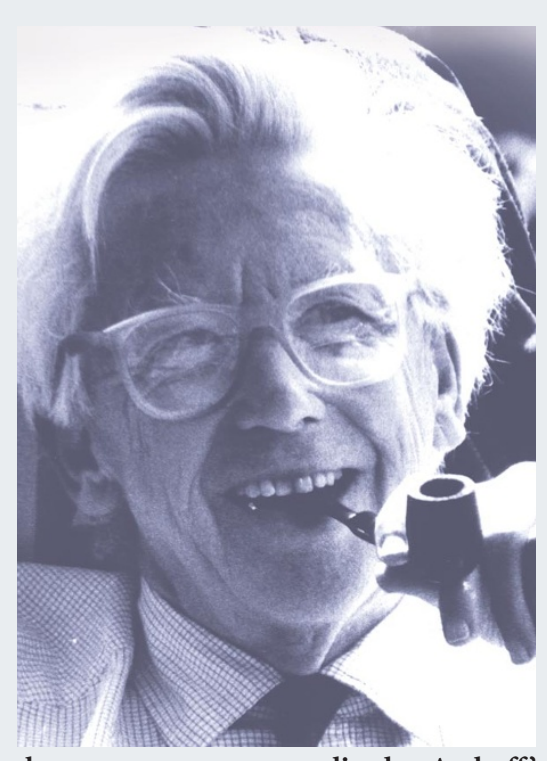

phenomenon soon generalized as Aschoff's rule.

These and other findings led to a new conceptual view of the synchronization of circadian rhythms. It postulated an innate biological oscillator which under natural conditions is synchronized with the Earth's rotation by the response to a 'zeitgeber' a word Aschoff coined and contributed to the English language. Applying physical oscillator theory, Aschoff was able to make and experimentally test predictions about the behaviour of circadian systems in response to different zeitgeber properties. His experimental and theoretical work in the 1950s and 1960s laid the basis for viewing circadian rhythms as the product of endogenous oscillators which derive their true functional significance from the maintenance of a constant phase relationship with the light-dark cycle the most precise zeitgeber the planet has to offer. The demonstration of localized lightsensitive circadian pacemakers by others in the 1970 s confirmed the validity of the approach.

Meanwhile, Aschoff went on to apply the same experimental approach to humans. He built an underground 'bunker', designed to study human subjects in prolonged isolation from time cues. Characteristically, he chose to be the first subject himself. In a series of investigations over 20 years he and his collaborator Rütger Wever firmly established that human physiology, behaviour and cognition are just as much controlled by endogenous 'circadian' oscillators as those of our fellow creatures. These findings had far-reaching effects on the medical sciences - arguably more fundamentally so than the work of Aschoff's influential father. It led to our current understanding of many socio-medical problems that stem from shift work, affective disorders, sleep disorders, ageing and jet lag. It also provided the basis for optimizing drugapplication schedules in pharmacological therapy.

The 'Abteilung Aschoff' at the MPIV in the picturesque village of Andechs exerted a magnetic attraction on researchers from a wide variety of backgrounds. Biologists, psychologists, mathematicians and physicians arrived to discuss their research. They learned to talk about biological rhythms in a common language. Aschoff had an unusual breadth of mind, a clear focus on basic principles and an encyclopaedic knowledge of diverse literatures. In some of his reviews, he laid the groundwork for emerging fields. For instance, he contributed the core-shell concept to thermoregulation; as early as 1955 , he forecasted the existence of endogenous circannual timers in annual reproduction; and he analysed human seasonal conception patterns and introduced the idea of a 'biological equator'.

Like Pittendrigh, Aschoff had a great talent for lecturing. He combined scientific creativity with joie de vivre and a warm personal interest in his fellow scientists. The atmosphere so created made a pilgrimage to the Mecca of biological rhythms research a lasting source of inspiration to scores of scientists.

After retiring in 1983, Aschoff returned to live in the stately mansion in which he was born, on the Ludwig Aschoff Platz in Freiburg. He maintained a continuous stream of original publications including many on the human sense of time - several of which are still in press. Aschoff's exuberant vitality was eventually broken when his lifelong partner Hilde Jung died, ten months ahead of him. She too was a warm and unconventional personality, who had a major share in creating the environment in which he flourished. They leave six children, 19 grandchildren and an uncountable number of scientific offspring. With his daring departures from established disciplines, Aschoff set an unforgettable example to those who had the privilege to know him and learn from him.

\section{Serge Daan and Eberhard Gwinner}

Serge Daan is in the Zoological Laboratory, University of Groningen, PO Box 14, 9750 AA Haren, The Netherlands. e-mail:S.Daan@biol.rug.nl

Eberhard Gwinner is in the Forschungsstelle für Ornithologie der Max-Planck-Gesellschaft, vonder-Tann-Strasse 7, 82346 Andechs, Germany. e-mail:gwinner@erl.ornithol.mpg.de 